\title{
In-flight Synthesis of Nanosized ZrC Particles from Various Precursors in RF Thermal Plasma
}

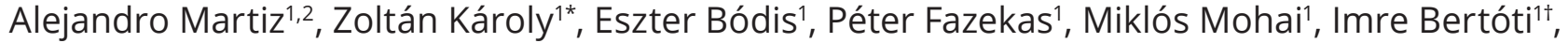 \\ Anna Mária Keszler ${ }^{1}$ \\ ${ }^{1}$ Institute of Materials and Environmental Chemistry, Research Centre for Natural Sciences, Magyar tudósok krt. 2. \\ 1117 Budapest, Hungary \\ ${ }^{2}$ Laboratory of Plastics and Rubber Technology, Department of Physical Chemistry and Materials Science, Budapest University of \\ Technology and Economics, Müegyetem rkp. 3. H/1, 1117 Budapest, Hungary \\ *Corresponding author, e-mail: karoly.zoltan@ttk.hu
}

Received: 31 May 2020, Accepted: 14 August 2020, Published online: 28 January 2021

\begin{abstract}
Synthesis of zirconium carbide ( $\mathrm{ZrC}$ ) powder was investigated applying a non-conventional atmospheric radiofrequency (RF) thermal plasma process. In one case, zirconium dioxide $\left(\mathrm{ZrO}_{2}\right)$ was reacted with solid carbon or with methane with varying molar ratio. In the other, zirconium-propoxide (NZP), containing both constituents, was thermally decomposed in the Ar plasma.

Temperature-dependent thermodynamic analysis was performed in the 500-5500 K temperature range to estimate the formation of possible equilibrium products for each reaction stoichiometry. Broad temperature range exists for the stability of solid ZrC for each explored reaction system. In accordance with this prediction, X-ray diffraction studies detected the $\operatorname{ZrC}$ as the major phase in all the prepared powders. The yield of particular runs ranged from $39 \%$ to $98 \%$. Practically, full conversion was typical for the case of NZP precursor, however only partial conversion could be detected in $\mathrm{ZrO}_{2}$ reactions.

The average particle size of the powders falls between $10 \mathrm{~nm}$ and $100 \mathrm{~nm}$ depending on the type of the reaction systems (either calculated from the specific surface area or derived from broadening the XRD reflections). The transmission electron micrographs indicated mostly globular shape of the nanosize particles. Quantitative analysis of the surface of the powders by X-ray photoelectron spectroscopy revealed the presence of oxygen and carbon. Evaluating the spectra of the powders prepared from NZP, and taking in the account its spherical shape, a $\mathrm{ZrC}$ core covered by a very thin $(\approx 1.0 \mathrm{~nm}) \mathrm{ZrO}_{2}$ layer may be accounted for the measured oxygen and a thicker carbonaceous layer.
\end{abstract}

Keywords

nanopowder synthesis, RF thermal plasma, ceramic nanopowders, zirconium carbide

\section{Introduction}

Zirconium carbide $(\mathrm{ZrC})$ is a unique ceramic material belonging to the class of ultra-high temperature ceramics (UHTC) and is an important non-oxide ceramic material with attractive physical and chemical properties, such as high hardness (28.7 GPa), high strength, high melting point $\left(3445^{\circ} \mathrm{C}\right)$, high chemical inertness and good thermal shock resistance. Based on these outstanding properties, $\mathrm{ZrC}$ is widely used in different ultra-high temperature applications, as cutting tools in the mechanical, as a coating in the nuclear industry and as reinforcing particles in wear-resistant materials and electrical devices. Furthermore, it is known as one of the main kinds of far infrared ceramics [1-4].
$\mathrm{ZrC}$, however, shows very poor sinterability, hindering its extensive applications. The latter can be improved by applying smaller particles.

Over the last decades, nanosized grain materials have gained increasing interests due to the absence of extended defects in these particles [5]. Nanosized $\mathrm{ZrC}$ can decrease the sintering temperature and facilitate densification processes due to the larger surface area and higher reactivity of the smaller particles [6]. Moreover, it was shown that sintered ceramics from ultrafine grain size powder may also improve their mechanical properties significantly [7-8]. 
The conventional synthesis of metal carbides generally involves the reduction of metal oxides in a carbon-rich environment. The carbothermal reduction method generally requires relatively high reaction temperatures, such as $1600-2200{ }^{\circ} \mathrm{C}$ and long reaction time, e.g., several hours in the case of $\mathrm{ZrC}$. In addition, these solid-state reactions result in powders with relatively large particle sizes. Hence in the case of many applications, additional milling is required, which tends to be expensive and may lead to contamination of the powder [9-10]. Several other methods have also been applied for $\mathrm{ZrC}$ synthesis, such as self-propagating high-temperature synthesis (SHS), pyrolysis and high energy ball milling [11-14], however, these synthesis routes yield again only submicron-sized particles. Meanwhile, only a few methods have been reported on preparing $\mathrm{ZrC}$ nanopowders. These are mainly solution-based processes, such as sol-gel or liquid polymer precursor methods [15-19].

Plasma processes are a special group of gas-phase reactions. A large number of publications, including a set of our previous papers, pointed out that due to its unique properties, thermal plasma processes offer an appealing route for preparing nanosized oxide, nitride, carbide and boride ceramic nanopowders [20-26]. Thermal plasmas possess extremely high temperatures (up to $15,000 \mathrm{~K}$ in the flame), large plasma volume, high enthalpy and high concentrations of chemically reactive species, enhancing the reactivity of the precursors injected in the plasmas [27-29]. Besides, the typically fast cooling rate $\left(10^{4} \mathrm{Ks}^{-1}\right)$ inhibits grain growth of the small molecular clusters thus promotes the formation of nanopowder. Plasma synthesis involves a one-step process, in which reactions take place within milliseconds, thus the production of nanopowders can be well controlled with operating time and applied specific power, providing possibility for mass production of nanoparticles with high rate. In addition to above listed advantages, the thermal plasma synthesis is flexible in terms of precursor material selection [30].

In some cases, for the preparation of different high-temperature transition metal carbides, oxide precursors were used in the plasma synthesis method $[30,31]$. Recently, using of organometallic precursors, containing both the metal and carbon constituents are preferred [32].

Plasma synthesis of nanosized $\mathrm{ZrC}$ powder was also carried out using hydrocarbon as carbon and zirconium(IV) chloride $\left(\mathrm{ZrCl}_{4}\right)$ as zirconium source [33]. The disadvantage of applying $\mathrm{ZrCl}_{4}$ precursor includes the formation of corrosive $\mathrm{HCl}$ as a reaction by-product.
In this study, we investigated the preparation of $\mathrm{ZrC}$ nanopowder in a radiofrequency (RF) thermal plasma using liquid (NZP) or solid $\left(\mathrm{ZrO}_{2}\right)$ as precursors. These two cases involve different evaporation and synthesis routes. In case of NZP, both elements of the $\mathrm{ZrC}$ are present in the precursor. Methane or graphite powder was used as carbon sources in the case of $\mathrm{ZrO}_{2}$. Involvement of $\mathrm{ZrO}_{2}$ in this study was motivated by consideration of a perspective mass production of $\mathrm{ZrC}$, because a cost-effective process can be based primarily on the readily available $\mathrm{ZrO}_{2}$.

\section{Experimental}

The experiments were carried out in an inductively coupled RF thermal plasma system using a five turn coil torch (TEKNA PL-35, TEKNA ltd., Canada) connected to a radio frequency (RF) generator (LEPEL, USA) with a maximum power of $30 \mathrm{~kW}$ at 4-5 MHz. The torch was mounted vertically on top of the reactor connected simultaneously to a cyclone and a vacuum pump. A detailed description of the system and schematic presentation is illustrated in our previous publications [34-36]. Zirconium(IV)-propoxide solution ( $\mathrm{NZP}: \mathrm{Zr}\left(\mathrm{OCH}_{2} \mathrm{CH}_{2} \mathrm{CH}_{3}\right)_{4} 70 \mathrm{wt} \%$ in 1-propanol, from Sigma-Aldrich) was applied as the zirconium and carbon source, the liquid was delivered by a peristaltic pump (Masterflex) to the atomizer probe placed in the center of plasma flame. The solid $\mathrm{ZrO}_{2}$ (Sigma-Aldrich, $40 \mu \mathrm{m}$ particle size) precursor was injected axially into the hottest zone of the plasma flame through a water-cooled probe by a powder feeder (PRAXAIR). When graphite powder (KS4, Timcal Co., mean particle size $2.8 \mu \mathrm{m}$ ) was used as carbon sources, it was mixed with the $\mathrm{ZrO}_{2}$ and fed together. The plasma (central) gas was a mixture of Ar and $\mathrm{He}$, where the role of helium is to increase heat conductivity and the enthalpy of the plasma [20], while Ar was used as sheath gas as well. The precursors were fed with a carrier gas of Ar, or in one case $\mathrm{N}_{2}$. The purity of these gases (Linde Gáz Magyarország Ltd.) was $99.996 \%$. In the other set of $\mathrm{ZrO}_{2}$ experiments, methane $(99.5 \%$, Messer Hungarogáz Ltd.) was introduced in the plasma reactor mixed with Ar in the sheath gas. The power was set to $25 \mathrm{~kW}$ for each run. The selection of working parameters (Table 1) was based on our previous experiments at the synthesis of different (oxide, boride) nanoparticles using the same equipment [23, 37-39]. In this study the following input ratios were explored: $\mathrm{ZrO}_{2}+3 \mathrm{C}, \mathrm{ZrO}_{2}+5 \mathrm{C}$, $\mathrm{ZrO}_{2}+2 \mathrm{CH}_{4}, \mathrm{ZrO}_{2}+3 \mathrm{CH}_{4}, \mathrm{NZP}$ and NZP $+15 \mathrm{~N}_{2}$.

Solid product for the analysis was collected from the inner surface of the reactor wall. 
Table 1 Experimental condition for the synthesis of $\mathrm{ZrC}$ nanoparticles

\begin{tabular}{|c|c|}
\hline \multicolumn{2}{|c|}{ Typical operating parameters in RF thermal plasma } \\
\hline Sheath gas and flow rate & Ar $30 \mathrm{dm}^{3} \mathrm{~min}^{-1}$ \\
\hline Plasma gas and flow rate & $\operatorname{Ar}-\mathrm{He}(15: 10) 25 \mathrm{dm}^{3} \mathrm{~min}^{-1}$ \\
\hline Carrier gas and flow rate & Ar or $\mathrm{N}_{2} 8 \mathrm{dm}^{3} \mathrm{~min}^{-1}$ \\
\hline RF power & $25 \mathrm{~kW}$ \\
\hline Reactor pressure & $80 \mathrm{kPa}$ \\
\hline
\end{tabular}

X-ray diffraction (XRD) patterns were obtained by a Philips PW 3710 instrument equipped with a PW 1050 Bragg-Brentano parafocusing goniometer, using monochromatized $\mathrm{Cu} \mathrm{K} \alpha$ radiation. The XRD scans were digitally recorded with steps of 0.041 in the 2 theta range from $4^{\circ}$ to $80^{\circ}$.

The quantitative phase composition was evaluated using a full profile fitting method with corrections for preferred orientation and micro absorption [40]. The specific surface area was measured by nitrogen adsorption at $77 \mathrm{~K}$ and evaluated based on BET isotherms (Autosorb 1C, Quantachrome, seven point isotherm).The average particle size of synthetized powders was calculated by the following relation: $\mathrm{SSA}=6 / \rho d$, where $\rho$ is the absolute particle density $\left(\mathrm{cm}^{3} \mathrm{~g}^{-1}\right), d$ is the diameter $(\mu \mathrm{m})$ of the spherical particles and SSA is the measured specific surface area $\left(\mathrm{m}^{2} \mathrm{~g}^{-1}\right)$.

The morphology of synthesized powders was characterized by scanning electron microscopy (SEM, Zeiss type DSM 982 GEMINI with a field emission tungsten cathode) equipped with energy dispersive X-ray analysis (EDX) and transmission electron microscopy (TEM, Morgagni 268D). Raman spectroscopy measurements were performed using a Horiba Jobin-Yvon LabRAM-type micro spectrometer equipped with an $\mathrm{Nd}-\mathrm{YAG}$ laser source, $40 \mathrm{~mW}$ laser power supplied with an Olympus BX-40 optical microscope. The measurements were carried out with $532 \mathrm{~nm}$ excitation wavelength, at low temperature $\left(-20^{\circ} \mathrm{C}\right)$ using a Linkam THMS600 temperature-controlled microscope stage. X-ray photoelectron spectra were recorded on a Kratos XSAM 800 spectrometer operating in fixed analyzer transmission mode, using $\mathrm{Mg} \mathrm{K} \alpha_{1,2}(1253.6 \mathrm{eV})$ excitation. The pressure of the analysis chamber was lower than $1 \times 10^{-7} \mathrm{~Pa}$. Photoelectron lines of the main constituent elements, i.e., the $\mathrm{Zr} 3 \mathrm{~d}, \mathrm{Cls}$ and $\mathrm{O} 1 \mathrm{~s}$, were recorded by $0.1 \mathrm{eV}$ steps. Spectra were referenced to the energy of the ${\mathrm{Zr} 3 \mathrm{~d}_{5 / 2}}$ line of the carbide type zirconium, set at $179.4 \pm 0.1 \mathrm{eV}$ binding energy (B.E.). Data were processed by the Kratos Vision 2 program, while the quantitative analysis, based on peak area intensities, and model calculations were performed by the XPS MultiQuant program [41, 42], using experimentally determined photo-ionization cross-section data of Evans et al. [43] and asymmetry parameters of Reilman et al. [44]. Surface composition was calculated by the "infinitely thick homogeneous sample" and layer thickness by the Layers-on-Sphere models. Chemical states of the constituent elements were identified and assigned by reference data-bases and publications $[45,46]$.

\section{Results}

\subsection{Thermodynamic calculations}

We calculated the thermodynamic equilibrium concentrations of the reactant and products using FACTSAGE [47] thermodynamic software based on the Gibbs free energy minimization method. The calculations were performed for atmospheric pressure in the 500-5500 K temperature range for the following systems:

1. $\mathrm{ZrO}_{2}+3 \mathrm{C}+\mathrm{Ar}$ (in excess),

2. $\mathrm{ZrO}_{2}+2 \mathrm{CH}_{4}+\mathrm{Ar}$ (in excess),

3. $\mathrm{ZrO}_{2}+3 \mathrm{CH}_{4}+\mathrm{Ar}$ (in excess),

4. $\mathrm{Zr}\left(\mathrm{OCH}_{2} \mathrm{CH}_{2} \mathrm{CH}_{3}\right)_{4}+\mathrm{Ar}$ (in excess),

5. $\mathrm{Zr}\left(\mathrm{OCH}_{2} \mathrm{CH}_{2} \mathrm{CH}_{3}\right)_{4}+15 \mathrm{~N}_{2}+\mathrm{Ar}$ (in excess).

Since Ar is not taking part in the plasma reactions, it will not be indicated in further descriptions.

During the evaluation of the results, it must be kept in mind that due to the short residence time of the species in the plasma, thermodynamic equilibrium might not be achieved. The results, however, allow to estimate the potential type and concentration of products with the assumption that the precursors evaporate and decompose completely (atomize) in the high-temperature region of the plasma and reaction occurs in the gas phase. Temperature distribution and reagent trajectories (particles, molecules, atoms, radicals, etc.) in the reactor are usually based on, somehow simplified, mathematical simulations [48, 49]. Another hypothesis is that the reaction product formed first can be considered as the final one as further reactions are kinetically hindered at lower temperature regions because of the short dwell time.

Fig. 1 (a) shows the equilibrium composition as the function of temperature for the case of $\mathrm{ZrO}_{2}$ and $\mathrm{C}$ precursor with 1:3 molar ratios. The main species in the gas phase at 3000-5500 $\mathrm{K}$ temperature range are atomic $\mathrm{Zr}$, $\mathrm{C}, \mathrm{O}$, small carbon clusters $\left(\mathrm{C}_{2}, \mathrm{C}_{3}\right)$ and oxygen-containing molecules such as $\mathrm{ZrO}$. Over $3000 \mathrm{~K}$ temperature $\mathrm{ZrO}_{2}$ is found practically in a reduced vapor phase, only $\mathrm{Zr}, \mathrm{C}$ and $\mathrm{CO}$ are present in a considerable amount thus between the $\mathrm{Zr}$ and $\mathrm{C}$ reaction is very likely to occur in the gas phase. The first condensed phase is $\mathrm{ZrC}$ that forms below $3500 \mathrm{~K}$, followed by carbon and $\mathrm{ZrO}_{2}$ below $2000 \mathrm{~K}$. 

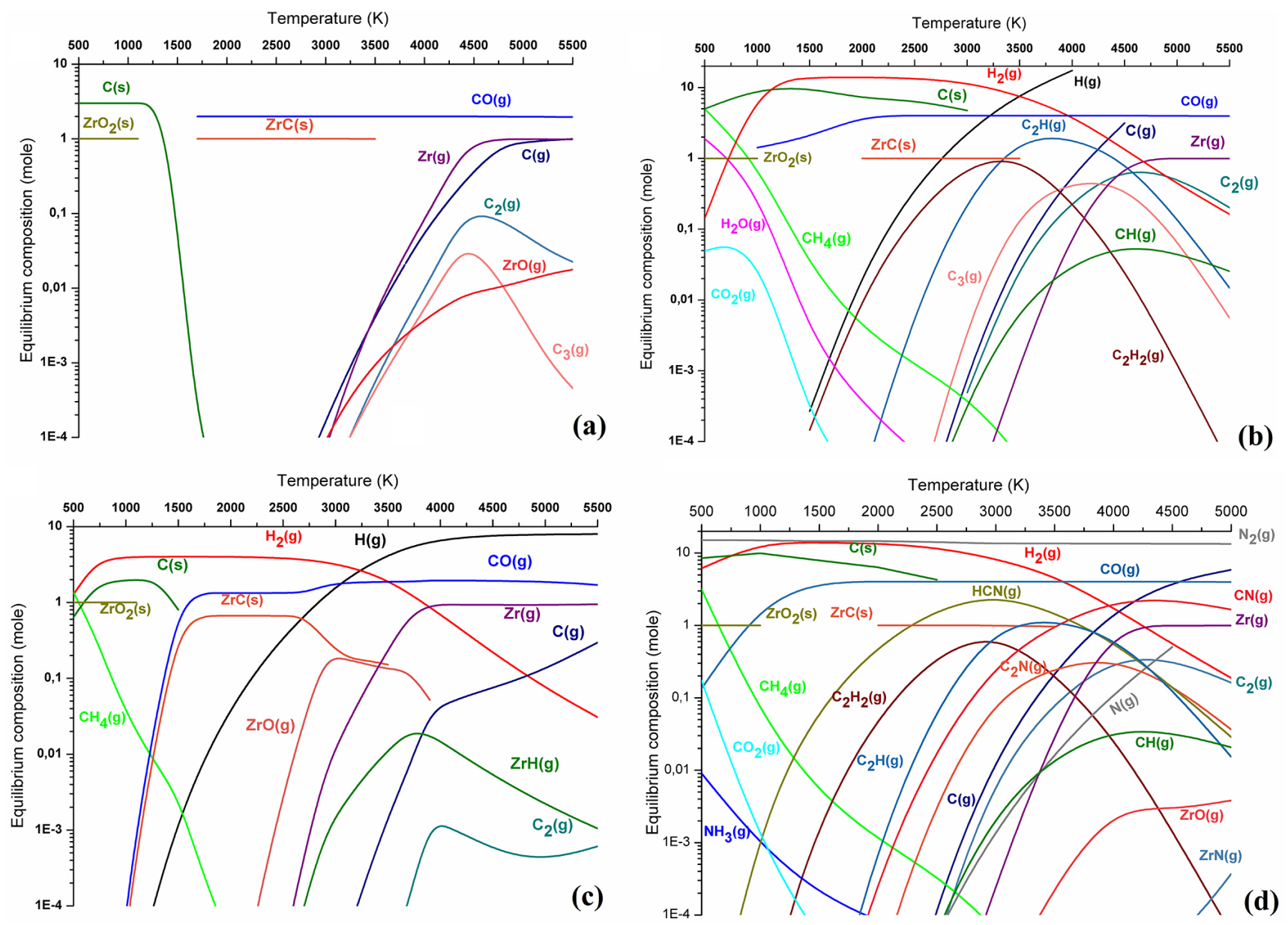

Fig. 1 Temperature dependent equilibrium composition of $\mathrm{ZrO}_{2}+3 \mathrm{C}$ (a), $\mathrm{ZrO}_{2}+2 \mathrm{CH}_{4}$ (b), $\mathrm{Zr}\left(\mathrm{OCH}_{2} \mathrm{CH}_{2} \mathrm{CH}_{3}\right)_{4}(\mathrm{c}), \mathrm{Zr}\left(\mathrm{OCH}_{2} \mathrm{CH}_{2} \mathrm{CH}_{3}\right)_{4}+15 \mathrm{~N}_{2}$ (d) systems

Thermodynamic equilibrium conditions of $\mathrm{ZrO}_{2}$ and $2 \mathrm{CH}_{4}$ system (Fig. 1 (b)) are quite similar to the former one regarding the prevailing species above $2000 \mathrm{~K}$. Due to methane addition atomic $\mathrm{H}$ and $\mathrm{H}_{2}$ molecules also appears at temperatures above $1000 \mathrm{~K}$. Zr-bearing gas-phase species found at the high temperatures (above $3000 \mathrm{~K}$ ) are atomic $\mathrm{Zr}$, and in a small extent $\mathrm{ZrO}$ and $\mathrm{ZrH}$ molecules. The first condensed state again is $\mathrm{ZrC}$ (below $3500 \mathrm{~K}$ ), while $\mathrm{ZrO}_{2}$ and carbon are developed only below $2000 \mathrm{~K}$.

Fig. 1 (c) illustrates the thermodynamic equilibrium composition for NZP. There are some significant differences comparing to former systems. First, NZP has much lower evaporation and decomposition temperature than $\mathrm{ZrO}_{2}$ thus once introduced in the high-temperature zone of the plasma complete evaporation and decomposition can be assumed. Furthermore, molar ratios of $\mathrm{O}, \mathrm{C}$ and $\mathrm{H}$ to $\mathrm{Zr}$ are considerably higher than in the previous systems. In other words, carbon is provided in a great excess that facilitates the formation of $\mathrm{ZrC}$. The prevailing species are quite the same as compared to former described systems, but their ratio reflects the increased molar ratio of $\mathrm{C}$ and $\mathrm{O}$ to $\mathrm{Zr}$ in the NZP molecule. Accordingly, $\mathrm{H}_{2}$ molecules are present at a higher concentration, while small hydrocarbons such as $\mathrm{C}_{2} \mathrm{H}_{2}, \mathrm{C}_{2} \mathrm{H}$ and $\mathrm{CH}$ also appear in the gas phase at a temperature already above $2000 \mathrm{~K}$. Carbon is available in the form of atomic carbon and small carbon clusters $\left(\mathrm{C}_{2}, \mathrm{C}_{3}\right)$ in a wide temperature range. The majority of the oxygen is irreversibly bound to carbon as $\mathrm{CO}$. When $\mathrm{CO}$ is formed in this system, it behaves essentially as an inactive gas, and these carbon and oxygen are unavailable for further reactions. The condensed phase below $3000 \mathrm{~K}$ comprises $\mathrm{ZrC}$ and carbon as well, while $\mathrm{ZrO}_{2}$ is formed below $2000 \mathrm{~K}$.

The addition of nitrogen to NZP (Fig. 1 (d)) diversifies the equilibrium compositions in the studied temperature range. Greatly increases the number of species with nitrogen-containing molecules such as $\mathrm{N}, \mathrm{CN},(\mathrm{CN})_{2}, \mathrm{HCN}, \mathrm{NH}$, $\mathrm{NO}$ above $2500 \mathrm{~K}$ and $\mathrm{NH}_{3}$ at temperature below $2000 \mathrm{~K}$. Even a small amount of $\mathrm{ZrN}(\mathrm{g})$ is present in the gas phase at high-temperature range (4500-5500 K). Nevertheless, it does not appear among the condensed phases. Similar to former systems, the first condensed phase is $\mathrm{ZrC}$ with a considerable amount of solid carbon, too. 
Results of the thermodynamic calculations (Fig. $1(\mathrm{a}-\mathrm{d})$ ) show that solid $\mathrm{ZrC}$ could be formed over a wide temperature range from 1700 to $3500 \mathrm{~K}$. In each case $\mathrm{ZrC}$ is the first solid phase formed at or below $3500 \mathrm{~K}$. However, for $\mathrm{ZrO}_{2}+2 \mathrm{CH}_{4}$ and $\mathrm{ZrO}_{2}+3 \mathrm{C}$ systems, the optimum temperature range for $\mathrm{ZrC}$ formation is narrower (2100-2800 K) than in case of the NZP system (1900-3600 K). It can be assumed that in each investigated system at higher temperatures, $\mathrm{ZrC}$ is the thermodynamically favored state. However, when the temperature of the system falls below $2000 \mathrm{~K}$ $\mathrm{ZrO}_{2}$ becomes thermodynamically favored. $\mathrm{ZrC}$ must be formed and condensed before the temperature falls below the aforementioned temperature.

The results of thermodynamic equilibrium calculations have shown that the complete reduction of the NZP or $\mathrm{ZrO}_{2}$ to $\mathrm{ZrC}$ can be achieved in the Ar, $\mathrm{N}_{2}-\mathrm{Ar}$, and methane-Ar mixture.

Thermodynamic computations certainly provide information about equilibrium states, but they did not take into consideration the kinetic limitations. The extremely high temperatures, steep gradients and the rapid cooling create unusual process conditions which, in some circumstances, can give rise to significant deviations from the calculated equilibrium $[50,51]$. In the plasma synthesis process, the typical residence times of particles in the plasma are in the order of several hundred ms [48], consequently, the time for condensed phase reactants evaporation and gasphase chemical reactions is very short. Due to this short residence time of the reactants in the plasma flame, many chemical reactions may not reach the equilibrium state. Nevertheless, these investigations may give hints of the thermal prehistory of the precursors in the plasma.

\subsection{Powder characterization}

In Table 2, the semi-quantitative composition, based on the XRD peak intensities [52], the average crystallite size of $\mathrm{ZrC}$ determined from the broadening of XRD peaks and particle sizes calculated from the specific surface area values of the prepared powders are presented.
The mean sizes of $\mathrm{ZrC}$ particles were calculated from the values of the specific surface areas (SSA) of the product powders, assuming dense spherical shape (Table 2). The SSA varied in the particular Runs within the range of $10-100 \mathrm{~m}^{2} \mathrm{~g}^{-1}$. The mean size was estimated to fall between $11 \mathrm{~nm}$ and $79 \mathrm{~nm}$.

\subsubsection{Crystallographic phase relations}

$\mathrm{X}$-ray diffraction analysis was performed on the plasma synthesized samples to investigate the phase composition and the crystallite size.

In Fig. 2 the typical X-ray diffraction patterns of some selected plasma products synthesized from different precursors (Runs 1, 3, 5, 6) are illustrated.

Using $\mathrm{ZrO}_{2}$ precursor (Run1-4), the product powder is mainly a mixture of carbon, monoclinic $\left(\mathrm{m}-\mathrm{ZrO}_{2}\right)$ and tetragonal $\left(\mathrm{t}-\mathrm{ZrO}_{2}\right)$ zirconia, while reflections of lower intensity also indicate the presence of $\mathrm{ZrC}$. Peak corresponding to graphitic carbon can be detected regardless graphite or methane was used in the reactions as carbon source. The presence of zirconia in the product implies that a considerable amount of the zirconia particles just travel through the plasma flame without evaporation or getting reacted with the carbon. The zirconia precursor is composed of both monoclinic and tetragonal crystalline phases in nearly equal ratio. The intensity of $\mathrm{m}-\mathrm{ZrO}_{2}$ and $\mathrm{t}-\mathrm{ZrO}_{2}$, however, slightly decreases with the increase of carbon. In the case of methane reduction agent, no $\mathrm{m}-\mathrm{ZrO}_{2}$ peaks reflections were observed.

It was found in several earlier papers $[9,53]$ that synthesis performed in oxygen-rich environment oxygen easily lead to the formation of oxycarbide $\left(\mathrm{ZrO}_{x} \mathrm{C}_{y}\right)$ phases, in which oxygen substitutes some part of carbon atoms in the $\mathrm{ZrC}$ lattice. According to the XRD diffractograms, however neither separate reflections nor expansion/distortion of the $\mathrm{ZrC}$ reflections could be observed, which would correspond to the formation of oxycarbide face in our experiments.

To reduce the residual $\mathrm{ZrO}_{2}$ content in the product, in Runs 2 and 4 excess carbon was applied. According to thermodynamic calculations, higher molar ratio of the

Table 2 Precursors and characteristics of the as-prepared powders

\begin{tabular}{|c|c|c|c|c|c|c|c|}
\hline \multirow{2}{*}{ Run } & \multirow{2}{*}{$\begin{array}{l}\text { Precursors } \\
\text { molar ratio }\end{array}$} & \multirow{2}{*}{ Carrier gas } & \multicolumn{3}{|c|}{ Phase composition of the product (wt $\%$ ) by XRD } & \multirow{2}{*}{$\begin{array}{l}\mathrm{ZrC} \text { crystallite size } \\
(\mathrm{nm}) \text { from XRD }\end{array}$} & \multirow[t]{2}{*}{$\operatorname{dBET}(\mathrm{nm})$} \\
\hline & & & $\mathrm{ZrC}$ & $\mathrm{ZrO}_{2}$ & $\mathrm{C}$ & & \\
\hline 1 & $\mathrm{ZrO}_{2}+3 \mathrm{C}$ & $\mathrm{Ar}$ & 41 & 53 & 6 & 37 & 79 \\
\hline 2 & $\mathrm{ZrO}_{2}+5 \mathrm{C}$ & $\mathrm{Ar}$ & 39 & 48 & 13 & 29 & 58 \\
\hline 3 & $\mathrm{ZrO}_{2}+3 \mathrm{CH}_{4}$ & $\mathrm{Ar}$ & 48 & 49 & 3 & 25 & 35 \\
\hline 4 & $\mathrm{ZrO}_{2}+4 \mathrm{CH}_{4}$ & Ar & 51 & 42 & 7 & 23 & 35 \\
\hline 5 & $\mathrm{Zr}\left(\mathrm{OCH}_{2} \mathrm{CH}_{2} \mathrm{CH}_{3}\right)_{4}$ & Ar & 98 & 2 & - & 17 & 11 \\
\hline 6 & $\mathrm{Zr}\left(\mathrm{OCH}_{2} \mathrm{CH}_{2} \mathrm{CH}_{3}\right)_{4}$ & $\mathrm{~N} 2$ & 95 & 5 & - & 19 & 15 \\
\hline
\end{tabular}




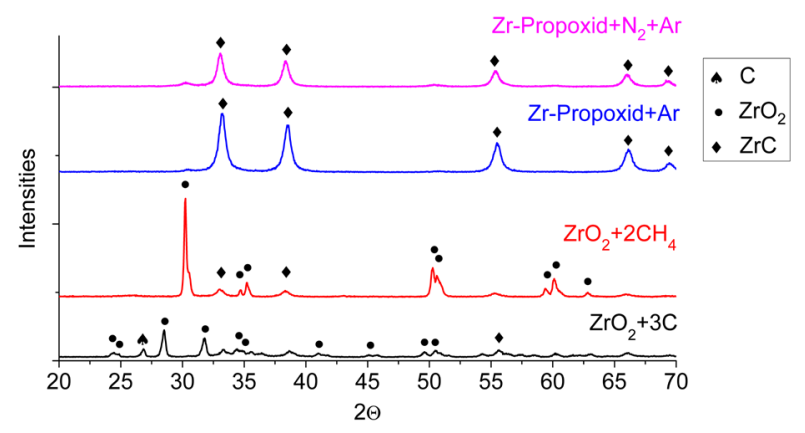

Fig. $2 \mathrm{X}$-ray diffraction patterns of plasma products from $\mathrm{ZrO}_{2}+3 \mathrm{C}$, $\mathrm{ZrO}_{2}+2 \mathrm{CH}_{4}, \mathrm{NZP}$ and NZP $+15 \mathrm{~N}_{2}$ precursors, respectively

carbon among the reactants increases the $\mathrm{ZrC}$ content of the product as well. However, it was not the case in our experiments. The addition of excess carbon did not promote the $\mathrm{ZrC}$ formation versus $\mathrm{ZrO}_{2}$ reduction rather only increase the solid carbon phase formation. Although thermodynamic calculations showed that reduction of $\mathrm{ZrO}_{2}$ to $\mathrm{ZrC}$ can be achieved in $\mathrm{ZrO}_{2}+3 \mathrm{C}$ or $\mathrm{ZrO}_{2}+2 \mathrm{CH}_{4}$ mixtures, XRD analysis indicates that only a part of the starting oxide was converted to $\mathrm{ZrC}$. This observation can be explained by the short residence times of $\mathrm{ZrO}_{2}$ particles in the plasma, being not enough for complete evaporation and decomposition for an in-flight reaction.

In Runs 5-6 using a NZP precursor, ZrC becomes the predominant phase. The sharp lines and absence of impurity peaks in the XRD pattern indicate the formation of the crystalline $\mathrm{ZrC}$ phase (Fig. 2). It has been reported in the literature that non-stoichiometric $\mathrm{ZrC}_{1-\mathrm{x}}$ could be formed in the $\mathrm{Zr}-\mathrm{C}$ binary system $[54,55]$. In our case, the calculated lattice parameters for $\mathrm{ZrC}$ powders are slightly higher $(4,699 \AA)$ than the standard value $4.693 \AA$ (PDF\#350784), however, in all experiments (Run 1-Run 6) the lattice parameter displays the same value. All the intense peaks correspond to face-center cubic (fcc) $\mathrm{ZrC}$ in agreement with the reference data indicating high structural purity of $\mathrm{ZrC}$.

The addition of nitrogen in the plasma resulted in the same phase composition: $\mathrm{ZrC}$ remained the dominant phase in the product, however its amount was slightly decreased and a small increase of the amount of $\mathrm{ZrO}_{2}$ was observed in Run 6 as compared to Run 5. The difference could be attributed to higher oxygen contamination of the plasma gases.

The thermodynamic calculation predicts that there is a strong tendency for the system (Runs 5 and 6) to form carbon in addition to $\mathrm{ZrC}$ over a wide temperature range. Starting from the NZP precursor, based on these calculations, carbon formation is expected in somewhat larger (Run 5) or lower (Run 6) quantities. However, in XRD patterns of these experiments the carbon phase could not be detected among the crystalline phases. Even when a carbon deposit has not been reported, it may be present in the product in the amorphous state [56]. Plasma processing of various aliphatic alcohols in reducing conditions can results in graphene layers instead of well crystallized carbon structure [57-58].

The average crystallite size of $\mathrm{ZrC}$ particles determined by the Scherrer equation based on the broadening of the reflections was found to be between 17 and $37 \mathrm{~nm}$ respectively. The highest value, with $37 \mathrm{~nm}$, was found in the reaction of $\mathrm{ZrO}_{2}+3 \mathrm{C}$ (Run 1) and the lowest, with $17 \mathrm{~nm}$ size, was found in the case of NZP precursor (Run 5).

\subsubsection{Particle morphology}

The TEM and the SEM image in Fig. 3 show the microstructure of the plasma synthesized product powder obtained from the $\mathrm{ZrO}_{2}+2 \mathrm{CH}_{4}$ reaction (Run 3). SEM image (Fig. 3 (a)) suggests a significant heterodispersity in the particle size. Some large spherical particles with a mean particle size of about $10 \mu \mathrm{m}$ and aggregates of sub-micron and more frequently, of nanometer size particles could be observed.
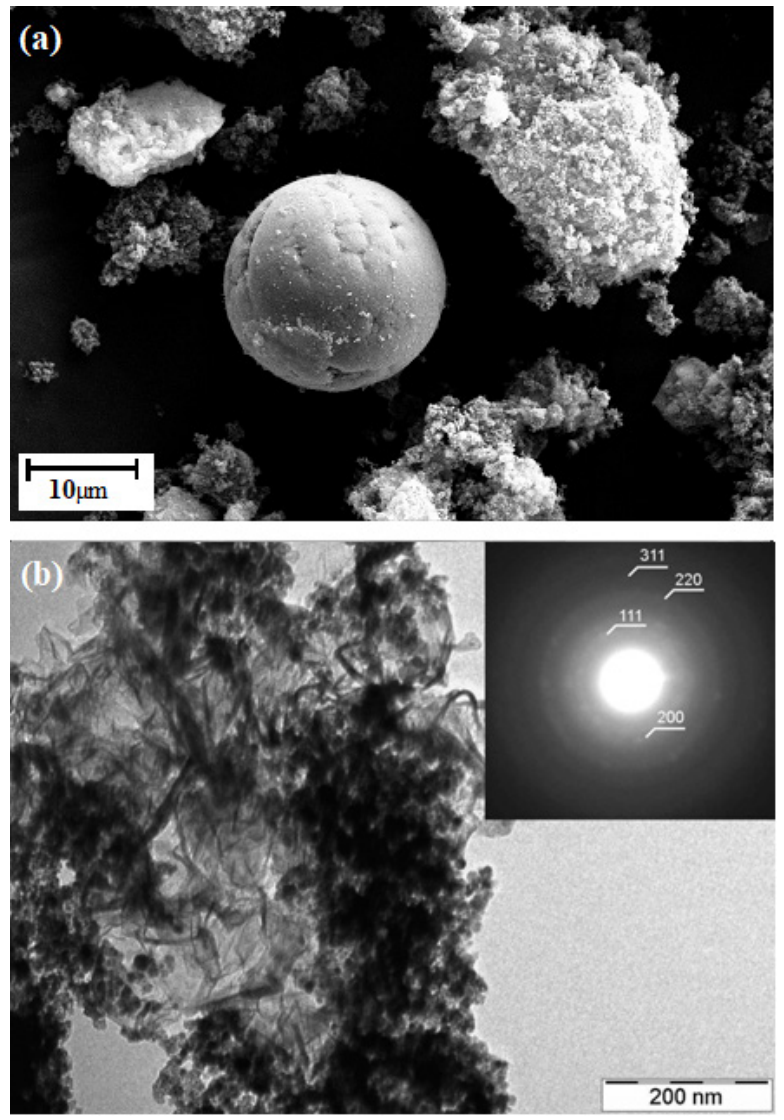

Fig. 3 SEM (a) and TEM (b) micrographs of the sample from $\mathrm{ZrO}_{2}+$ $2 \mathrm{CH}_{4}$ precursors 
EDX analysis revealed that the larger spheres are $\mathrm{ZrO}_{2}$ particles, while the aggregates are composed of zirconium and carbon.

The larger zirconia particles represent the unreacted part of the zirconia precursor. Theoretically, the precursor $\mathrm{ZrO}_{2}$ particles passing through the plasma flame should evaporate. However, part of them neither evaporate nor dissociate due to the insufficient dwell time in the hottest zone of the plasma. The appropriate residence time varies depending on both the size and the actual thermal trajectory of the individual particles. The spherical shapes of the particle suggest, however, that it was also affected, melted or partially evaporated in the plasma. The small size and the relatively smooth surface indicate also significant recrystallization of the precursor $\mathrm{ZrO}_{2}$ particles. $\mathrm{ZrC}$ is formed by homogenous nucleation from the gas phase. Due to high cooling rates characteristic for in-flight plasma conditions, the nucleated particles do not have the chance to grow further but tend to deposit on the reactor wall or fly away with the gas stream into the filter unit.

Although the SEM images of the products from the $\mathrm{ZrO}_{2}$ precursor show similar morphology (Fig. 3 (a) and Fig. 4 (a)), in TEM micrographs, we observed differences. The TEM image of the $\mathrm{ZrO}_{2}+3 \mathrm{CH}_{4}$ reaction (Fig. 3 (b)) shows the presence of dark 10-50 nm size grains embedded in a light contrast, presumably graphitic material. The electron diffraction pattern corresponds to crystalline $\mathrm{ZrC}$.

TEM micrograph of the product resulted from the $\mathrm{ZrO}_{2}+3 \mathrm{C}$ reaction (Fig. 4 (b)) is in accordance with the XRD results showing three different phases: the darkest crystallites could be assigned to $\mathrm{ZrC}$, the more transparent grains to the $\mathrm{ZrO}_{2}$ phase, while the lightest ones to carbon. This is made on the basis of the different absorption coefficients of electrons increasing with the concentration of the high atomic number element, i.e. to the zirconium content of the phase.

The smallest mean particle size of $11 \mathrm{~nm}$ was obtained for the sample prepared from NZP precursor (Run 5). TEM micrographs (Fig. 5) of this sample fully confirm the above cited small size of mainly equiaxied particles. The mean size of $\mathrm{ZrC}$ particles were calculated from the values of the specific surface areas (SSA) of the product powders assuming dense spherical shape (Table 2). Although this assumption may not be completely satisfied, the obtained results are in agreement not only with SEM and TEM analysis (Figs. 3-5) but also with the average crystallite size of $\mathrm{ZrC}$ particles calculated from XRD patterns.
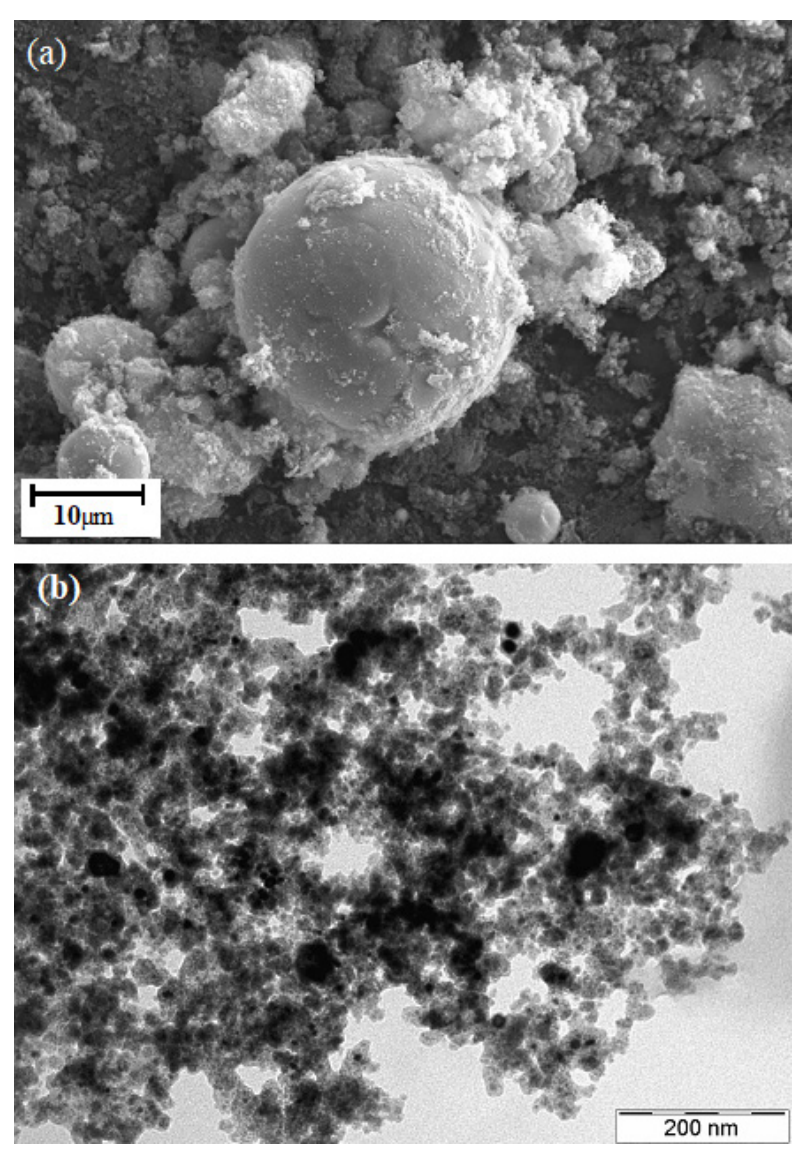

Fig 4 SEM (a) and TEM (b) micrographs of the sample from $\mathrm{ZrO}_{2}+3 \mathrm{C}$ precursors

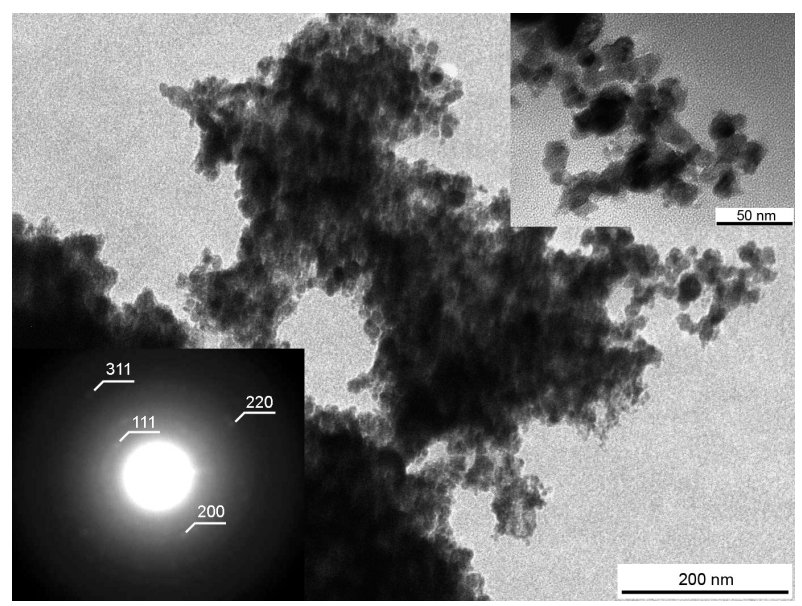

Fig. 5 TEM picture of the product obtained from NZP

\subsubsection{Raman spectroscopy}

Raman spectra were recorded only for samples prepared from NZP precursor (Run 5, Run 6) and shown in Fig. 6.

According to previous studies [59], stoichiometric $\mathrm{ZrC}$, due to its perfect $\mathrm{NaCl}$ structure, shows no peaks for Raman spectra, meanwhile for nonstoichiometric $\mathrm{ZrC}_{1-\mathrm{x}}$ phonon optical and acoustic branches associated to the presence of carbon vacancies were observed in the range 


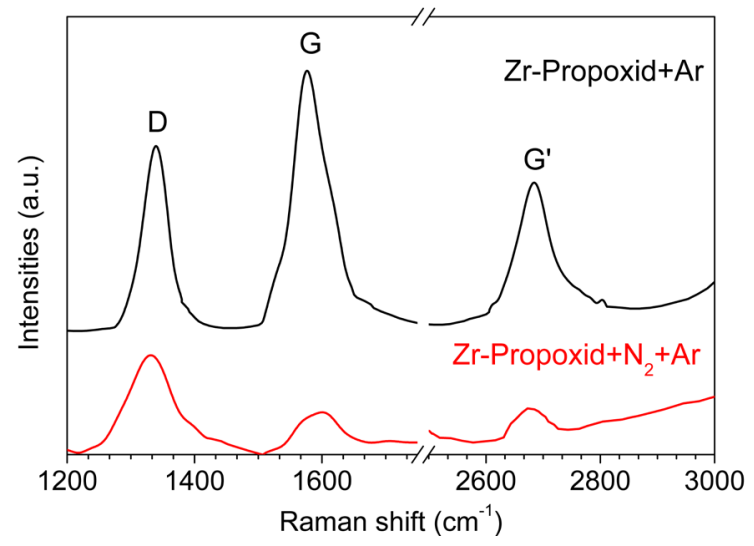

Fig. 6 Raman spectra of samples prepared from NZP precursor

of 200-300 $\mathrm{cm}^{-1}$ and $500-600 \mathrm{~cm}^{-1}$. Peaks corresponding to $\mathrm{ZrC}_{1-\mathrm{x}}$ did not occur in our spectra, thus these lowfrequency ranges are not depicted in Fig. 6. However, as no peaks corresponding to $\mathrm{ZrC}_{1-\mathrm{x}}$ were detected the synthesized $\mathrm{ZrC}$ can be considered to be stoichiometric.

The spectra show intensive bands at $\sim 1350 \mathrm{~cm}^{-1}$, $\sim 1580 \mathrm{~cm}^{-1}$ and $\sim 2700 \mathrm{~cm}^{-1}$, characteristic for carbon. The peak at $1588 \mathrm{~cm}^{-1}$ is conventionally referred as the $\mathrm{G}$ mode and assigned to the $\mathrm{C}-\mathrm{C}$ stretching vibration $\left(\mathrm{E}_{2 \mathrm{~g}}\right)$ of graphite, while the peak at $1340 \mathrm{~cm}^{-1}$ is called disorder-induced D-band. The peak observed at $2684 \mathrm{~cm}^{-1}$ originates from a second-order process and is referred as $\mathrm{G}^{\prime}$ band.

The intensity of the $\mathrm{D}$ and $\mathrm{G}$ and also the $\mathrm{G}^{\prime}$ peaks decrease significantly with the addition of $\mathrm{N}_{2}$, indicating the decrease of residual carbon in the powders. At the same time the decrease of the graphitic peak was more pronounced relative to the $\mathrm{D}$ band.

As it was emphasized, till the $D$ to $G$ band ratio of $\mathrm{I}(\mathrm{D}) / \mathrm{I}(\mathrm{G})$ represents the concentration of defects in graphite [1], the number of graphitic or graphene layers can be associated with the FWHM of the $\mathrm{G}^{\prime}$ band and the $\mathrm{I}\left(\mathrm{G}^{\prime}\right) / \mathrm{I}(\mathrm{G})$ ratio [32]. It was assumed that the number of graphitic or graphene layers decreases when the $\mathrm{I}\left(\mathrm{G}^{\prime}\right) / \mathrm{I}(\mathrm{G})$ ratio increases and the FWHM $\left(\mathrm{G}^{\prime}\right)$ decreases $[32,60]$.

For sample Run 5, the $\mathrm{I}(\mathrm{D}) / \mathrm{I}(\mathrm{G})$ ratio is 0.79 , FWHM $\left(\mathrm{G}^{\prime}\right)$ is $69 \mathrm{~cm}^{-1}$ while the ratio of $\mathrm{I}\left(\mathrm{G}^{\prime}\right) / \mathrm{I}(\mathrm{G})$ is 0.51 . For Run 6 these values are: $1.56,56 \mathrm{~cm}^{-1}$ and 0.73 , respectively. The degree of structural order, which is related to the ratio of $\mathrm{I}(\mathrm{D}) / \mathrm{I}(\mathrm{G})$, is higher in sample of Run 5 as compared to Run 6 when nitrogen was added to the system.

Evaluation of the number of graphene layers based on reported estimation $[32,60]$, is found to be more than 10 layers for Run 5, while for Run 6 turned to be between 5 and 10 layers, only. These small values are in full agreement with the TEM observations about the presence of transparent carbon layers. The presence of excited $\mathrm{N}_{2}$ atoms seems to partially inhibit the formation of the well-ordered graphite phase.

\subsubsection{Surface analysis}

The surface characteristics of the as-prepared powder samples were characterized by XPS.

Besides the expected $\mathrm{Zr}$ and $\mathrm{C}$, oxygen was also detected. All constituents are present in several chemical states, as illustrated by the decomposed $\mathrm{Zr} 3 \mathrm{~d}$ and $\mathrm{C} 1 \mathrm{~s}$ spectra in Fig. 7. Zirconium is found in carbide, $\mathrm{Zr3d5/2}$

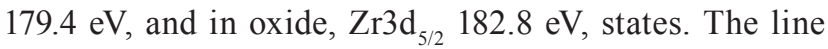
positions of the corresponding carbon, C1s $182.0 \mathrm{eV}$, and oxygen, O1s $531.2 \mathrm{eV}$, are in agreement with the literature data [45]. The appearance of the $\mathrm{ZrO}_{2}$ minor phase can be attributed to the high affinity between $\mathrm{Zr}$ and $\mathrm{O}[61,62]$. Part of the oxygen is chemically bound to carbon, $\mathrm{O} 1 \mathrm{~s} 533.0 \pm 0.2 \mathrm{eV}, \mathrm{C} 1 \mathrm{~s} 286.7 \pm 0.2 \mathrm{eV}$. In the case of sample Run 4, due to the separate carbon particles (as revealed by electron microscopy), differential charging can be observed, causing an extra $\mathrm{C} 1$ s component (peak labeled $\mathrm{C}^{*}$ in Fig. 7). The majority of the
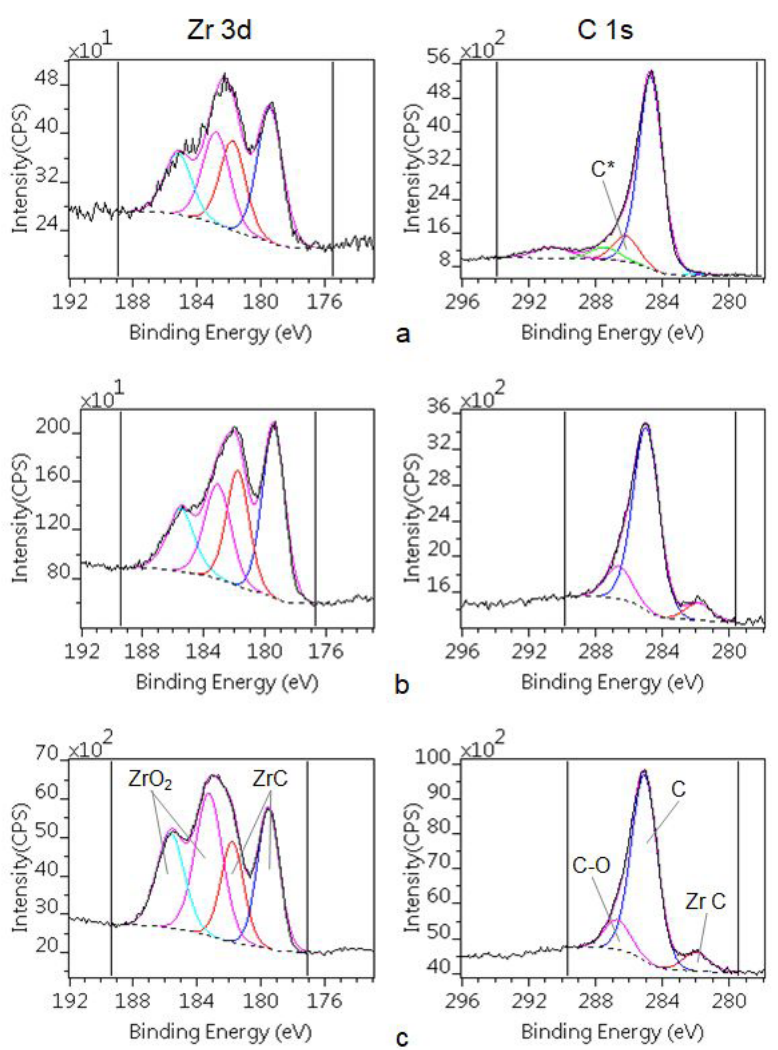

Fig. 7 X-ray photoelectron spectra of the $\mathrm{Zr} 3 \mathrm{~d}$ and $\mathrm{C} 1 \mathrm{~s}$ lines of the $\mathrm{ZrC}$ products prepared from various precursors: $\mathrm{ZrO}_{2}+2 \mathrm{CH}_{4}$ (a), NZP (b) and $\mathrm{NZP}+15 \mathrm{~N}_{2}(\mathrm{c})$ 
carbon is in elemental state, C1s $284.6 \pm 0.2 \mathrm{eV}$, forming together with the oxidized carbon the "carbonaceous" contamination on the samples.

The surface chemical compositions are shown in Table 3. Although the composition is calculated by the Homogeneous model, these samples are not homogeneous thus these values can be regarded semi-quantitative. A large amount of excess carbon is inevitably demonstrated. The ratios of the constituents of the main components $\left(\mathrm{ZrC}, \mathrm{ZrO}_{2}\right)$ are quite close to their expected values $(1: 1,1: 2)$.

For the NZP + Ar and NZP $+15 \mathrm{~N}_{2}$ samples, the level of the carbonaceous contamination is significantly lower and no separate carbon particles detected by SEM. Supposing that the oxide covers directly the carbide particles then the carbonaceous layer is formed on the surface of nanoparticles (due to decomposition of the hydrocarbons or propoxide, which are present in the gas phase), the thickness of these layers can be calculated. The results are presented in Table 4. The thickness values are in harmony with the composition data. For NZP + Ar the carbon layer is thicker while the oxide layer is thinner, comparing to $\mathrm{NZP}+15 \mathrm{~N}_{2}$.

Assuming that the as-calculated carbon layer is actually made up of graphene sheets, and evaluating the number of graphene layers appeared as 12 layers for Run 5, while for Run 6 as 10 layers (calculated with $0.33 \mathrm{~nm}$ distances between the layers), which are in excellent agreement with the values derived from Raman spectra.

Nanometer-sized ZrC particles have poor oxidation resistance. However, oxidation resistance can be improved by means of coating [1]. Graphitic carbon-coated nanoparticles are intensively studied worldwide, expecting that the carbon shell in these structures would be able to protect the inner core materials, i.e., it can protect $\mathrm{ZrC}$ nanoparticles in oxidative environment (Runs $5 \& 6$ in the present study) [1].

Table 3 Surface composition (atomic \%) of the various samples calculated by the Homogeneous model

\begin{tabular}{lccccccc}
\hline Precursor & $\mathrm{ZrC}$ & $\mathrm{C} \mathrm{Zr}$ & $\mathrm{ZrO}$ & $\mathrm{O} \mathrm{Zr}$ & $\mathrm{C}$ & $\mathrm{C} \mathrm{O}$ & $\mathrm{O} \mathrm{C}$ \\
\hline $\mathrm{ZrO}_{2}+2 \mathrm{CH}_{4}$ & 0.7 & 0.7 & 0.5 & 1.5 & 89.2 & 5.9 & 1.6 \\
$\mathrm{NZP}+\mathrm{Ar}$ & 6.5 & 5.8 & 4.3 & 7.0 & 61.7 & 11.0 & 3.8 \\
$\mathrm{NZP}+15 \mathrm{~N}_{2}$ & 5.5 & 5.6 & 6.7 & 12.8 & 54.1 & 8.6 & 6.7 \\
\hline
\end{tabular}

Table 4 Thickness (nm) of the carbonaceous and oxide layers on the $\mathrm{Zr}$ carbide particles, calculated by the Layers-on-Sphere model from XPS data

\begin{tabular}{lcc}
\hline Precursor & $\mathrm{CHx}$ layer $(\mathrm{nm})$ & $\mathrm{ZrO}_{2}$ layer $(\mathrm{nm})$ \\
\hline $\mathrm{NZP}+\mathrm{Ar}$ & 4.2 & 1.0 \\
$\mathrm{NZP}+15 \mathrm{~N}_{2}$ & 3.5 & 1.6 \\
\hline
\end{tabular}

However, when nanopowder is used as precursor for a sintered body, the presence of free carbon on the surface might prevent sintering. Heat treatment in hydrogen atmosphere would be required to prepare carbon free $\mathrm{ZrC}$ phase.

\section{Conclusions}

- Feasibility of preparation of nanosize $\mathrm{ZrC}$ in thermal plasma from $\mathrm{ZrO}_{2}$ reacting with carbon or $\mathrm{CH}_{4}$ and by thermal decomposition of NZP using high-temperature (HT) atmospheric plasma conditions is presented.

- Thermodynamic calculations predict the formation of solid $\mathrm{ZrC}$ in certain temperature ranges for all of the selected precursors and their relative proportions. The common temperature range of solid $\mathrm{ZrC}$ formation for each explored reaction system may be between approx. 2000 and $3000 \mathrm{~K}$, what is in the cooling tail of the plasma flame. In agreement with the thermodynamic calculations, XRD results confirm the presence of crystalline $\mathrm{ZrC}$ in all prepared samples. From here, it became evident that there must be a somewhat similar thermal prehistory of the reaction partners in the conducted experiments.

- Nanometric size powders were produced in each experiment, although with different mean particle size and chemical composition. The highest yield of $98 \%$ was achieved when nanopowders were prepared by the decomposition of NZP, while $\mathrm{ZrO}_{2}$ reacted with $\mathrm{C}$ resulted in the lowest yield of $39 \%$. In the case of $\mathrm{ZrO}_{2}$, the starting oxide could only be partially converted to $\mathrm{ZrC}$ at the applied reaction conditions.

- NZP was completely converted to crystalline $\mathrm{ZrC}$, this implies that the four Zr-O bonds are fully dissociated, and the $\mathrm{Zr}$ reacted with the carbon-containing species evolved from the propoxide part of the molecules. Only negligible amount of $\mathrm{ZrO}_{2}$ appeared in the resulted powder. The excess carbon from the propoxide chain form solid carbon.

- The particle size of the prepared samples falls in the range of 10-100 $\mathrm{nm}$ depending on the type of precursors. The smallest mean particle size, $11 \mathrm{~nm}$, was achieved with the NZP precursor. Important to note that very similar values were obtained for each type of sample, notwithstanding they are calculated from the specific surface area or from the broadening of the X-ray diffraction reflections, and also from the visual observation by TEM. Besides, this fact implies that all of these HT-plasma deposited 
samples are rather compact, not having internal pores with extended surface area, and also that the second solid phase, carbon, does not affect those measured particle size values significantly.

- XPS characterization revealed that even the structurally pure ZrC samples, derived from the NZP, contain some amount of oxygen and carbon on their surface. Supposing an oxide and carbonaceous layers on the surface of the spherical ZrC nanoparticles, an $\approx 1 \mathrm{~nm}$ oxide and a $\approx 4.1 \mathrm{~nm}$ thick carbon layer was calculated from Run 5 sample, but somewhat thicker oxide but thinner carbon layer was obtained for Run 6 when nitrogen was added to the process gas.

- Based on the above mentioned results, the process requires optimization with $\mathrm{ZrO}_{2}$ precursor towards completeness, and with NZP, towards the elimination of the excess solid carbon, e.g. by gasification (into

\section{References}

[1] Chen, L., Iwamoto, C., Omurzak, E., Takebe, S., Okudera, H., Yoshiasa, A., Sulaimankulova, S., Mashimo, T. "Synthesis of zirconium carbide $(\mathrm{ZrC})$ nanoparticles covered with graphitic "windows" by pulsed plasma in liquid", RSC Advances, 1(6), pp. 1083-1088, 2011.

https://doi.org/10.1039/C1RA00194A

[2] Sondhi, A., Morandi, C., Reidy, R. F., Scharf, T. W. "Theoretical and experimental investigations on the mechanism of carbothermal reduction of zirconia", Ceramics International, 39(4), pp. 4489-4497, 2013.

https://doi.org/10.1016/j.ceramint.2012.11.043

[3] Das, K., Bandyopadhyay, T. K. "Synthesis and characterization of zirconium carbide-reinforced iron-based composite", Materials Science and Engineering: A, 379(1-2), pp. 83-91, 2004.

https://doi.org/10.1016/j.msea.2003.12.022

[4] Sun, W., Xiong, X., Huang, B., Li, G., Zhang, H., Chen, Z., Zheng, X. "ZrC ablation protective coating for carbon/carbon composites", Carbon, 47(14), pp. 3368-3371, 2009. https://doi.org/10.1016/j.carbon.2009.07.047

[5] Tao, X. Y., Qiu, W. F., Li, H. "Synthesis of Nanosized Zirconium Carbide $(\mathrm{ZrC})$ by a Polymeric Precursor Route", Advanced Materials Research, 393-395, pp. 373-376, 2012. https://doi.org/10.4028/www.scientific.net/AMR.393-395.373

[6] Chaim, R., Levin, M., Shlayer, A., Estournes, C. "Sintering and densification of nanocrystalline ceramic oxide powders: a review", Advances in Applied Ceramics, 107(3), pp. 159-169, 2013. https://oi.org/10.1179/174367508X297812

[7] Rice, R. W. "Mechanical Properties of Ceramics and Composites: Grain And Particle Effects", CRC Press, New York, NY, USA, 2000. https://doi.org/10.1201/9780203908471

[8] Balla, A., Moczó, J., Károly, Z. "Co-Ni-Zn Ferrites Fabricated by Spark Plasma Sintering", Periodica Polytechnica Chemical Engineering, 64(2), pp. 265-270, 2020.

https://doi.org/10.3311/PPch.14710
$\mathrm{CO}$ ), if the further application requires it. However, considering some practical aspects of these results, the nanometer range particle size of the samples, synthesized by such HT-plasma technique, is beneficial in the process of hi-tech $\mathrm{ZrC}$ ceramics.

\section{Acknowledgments}

Authors thank Dr. P. Németh from the Institute of Materials and Environmental Chemistry, Research Centre for Natural Sciences for his very valuable help in TEM analysis and L. Gulyás for technical assistance in XPS measurements. The authors acknowledge the support given by the Hungarian National Research Development and Innovation Office for the funding of project No. VEKOP2.3.2-16-2017-00013 supported by the European Union and the State of Hungary, co-financed by the European Regional Development Fund.

[9] Yan, Y., Huang, Z., Liu, X., Jiang, D. "Carbothermal synthesis of ultra-fine zirconium carbide powders using inorganic precursors via sol-gel method", Journal of Sol-Gel Science and Technology, 44, pp. 81-85, 2007.

https://oi.org/10.1007/s10971-007-1595-X

[10] Ben Zine, H. R., Balázsi, K., Balázsi, C. "The Effect of the Chemical Composition to the End-Properties of Ceramic Dispersed Strengthened 316L/Y2O3 Composites", Periodica Polytechnica Chemical Engineering, 63(3), pp. 370-377, 2019. https://doi.org/10.3311/PPch.13591

[11] Song, M., Huang, B., Zhang, M., Li, J. "Reaction Synthesis of Nanoscale ZrC Particulates by Self-propagating High-temperature Synthesis from Al-Zr-C Powder Mixtures", ISIJ International, 48(7), pp. 1026-1029, 2008.

https://doi.org/10.2355/isijinternational.48.1026

[12] Li, J., Fu, Z. Y., Wang, W. M., Wang, H., Lee, S. H., Niihara, K. "Preparation of $\mathrm{ZrC}$ by self-propagating high-temperature synthesis", Ceramics International, 36(5), pp. 1681-1686, 2010. https://doi.org/10.1016/j.ceramint.2010.03.013

[13] Li, Q., Dong, S., Wang, Z., Hu, J., Wu, B., Zhou, H., He, P., Yang, J. "Fabrication of a $\mathrm{ZrC}-\mathrm{SiC}$ matrix for ceramic matrix composites via in-situ reaction and its application", Ceramics International, 39(1), pp. 877-881, 2013.

https://doi.org/10.1016/j.ceramint.2012.06.030

[14] Dong, J., Shen, W., Liu, X., Hu, X., Zhang, B., Kang, F., Gu, J., Li, D., Chen, N. P. "A new method synthesizing the encapsulated ZrC with graphitic layers", Materials Research Bulletin, 36(5-6), pp. 933-938, 2001. https://doi.org/10.1016/S0025-5408(01)00517-7

[15] Dollé, M., Gosset, D., Bogicevic, C., Karolak, F., Simeone, D., Baldinozzi, G. "Synthesis of nanosized zirconium carbide by a sol-gel route", Journal of European Ceramic Society, 27(4) pp. 2061-2067, 2007. https://doi.org/10.1016/j.jeurceramsoc.2006.06.005 
[16] Rambo, C. R., Cao, J., Rusina, O., Sieber, H. "Manufacturing of biomorphic ( $\mathrm{Si}, \mathrm{Ti}, \mathrm{Zr}$ )-carbide ceramics by sol-gel processing", Carbon, 43(6), pp. 1174-1183, 2005.

https://doi.org/10.1016/j.carbon.2004.12.009

[17] Umalas, M., Hussainova, I., Reedo, V., Young, D.-L., Cura, E., Hannula, S.-P., Lõhmus, R., Lõhmus, A. "Combined sol-gel and carbothermal synthesis of $\mathrm{ZrC}-\mathrm{TiC}$ powders for composites", Materials Chemistry and Physics, 153, pp. 301-306, 2015. https://doi.org/10.1016/j.matchemphys.2015.01.017

[18] Hasegawa, I., Fukuda, Y., Kajiwara, M. "Inorganic-organic hybrid route to synthesis of $\mathrm{ZrC}$ and $\mathrm{Si}-\mathrm{Zr}-\mathrm{C}$ fibres", Ceramics International, 25(6), pp. 523-527, 1999. https://doi.org/10.1016/S0272-8842(97)00089-8

[19] Liu, C., Li, K., Li, H., Zhang, S., Zhang, Y., Wang, B. "Synthesis, characterization and ceramization of a carbon-rich zirconium-containing precursor for $\mathrm{ZrC}$ ceramic", Ceramics International, 40(5), pp. 7285-7292, 2014

https://doi.org/10.1016/j.ceramint.2013.12.069

[20] Fridman, A. "Plasma Chemistry", Cambridge University Press, London, UK, 2008. https://doi.org/10.1017/CBO9780511546075

[21] Vollath, D. "Plasma synthesis of nanopowders", Journal of Nanoparticle Research, 10, pp. 39-57, 2008. https://doi.org/10.1007/s11051-008-9427-7

[22] Károly, Z., Mohai, I., Klébert, S., Keszler, A., Sajó, I. E., Szépvölgyi, J. "Synthesis of SiC powder by RF plasma technique", Powder Technology, 214(3), pp. 300-305, 2011. https://doi.org/10.1016/j.powtec.2011.08.027

[23] Szépvölgyi, J., Mohai, I., Karoly, Z., Gál, L. "Synthesis of nanosized ceramic powders in a radiofrequency thermal plasma reactor", Journal of the European Ceramic Society, 28(5), pp. 895-899, 2018. https://doi.org/10.1016/j.jeurceramsoc.2007.09.034

[24] Klébert, Sz. Keszler, A. M., Sajó, I., Drotár, E., Bertóti, I., Bódis, E., Fazekas, P., Károly, Z., Szépvölgyi, J. "Effect of the solid precursors on the formation of nanosized TiBx powders in RF thermal plasma", Ceramics International, 40(3), pp. 3925-3931, 2014. https://doi.org/10.1016/j.ceramint.2013.08.036

[25] Mohai, I., Gál, L., Szépvölgyi, J., Gubicza, J., Farkas, Z. "Synthesis of nanosized zinc ferrites from liquid precursors in RF thermal plasma reactor", Journal of the European Ceramics Society, 27 (2-3), pp. 941-945, 2017.

https://doi.org/10.1016/j.jeurceramsoc.2006.04.128

[26] Kim, M., Oh, J.-H., Kim, T.-H., Lee, Y. H., Hong, S.-H., Choi, S. "Synthesis of Metal Boride Nanoparticles Using Triple Thermal Plasma Jet System", Journal of Nanoscience and Nanotechnology, 19(10), pp. 6264-6270, 2019. https://doi.org/10.1166/jnn.2019.17026

[27] Ishigaki, T. "Synthesis of Functional Oxide Nanoparticles Through RF Thermal Plasma Processing", Plasma Chemistry and Plasma Processing, 37, pp. 783-804, 2017. https://doi.org/10.1007/s11090-017-9788-8

[28] Fronczak, M., Fazekas, P., Károly, Z., Hamankiewicz, B., Bystrzejewski, M. "Continuous and catalyst free synthesis of graphene sheets in thermal plasma jet", Chemical Engineering Journal, 322, pp. 385-396, 2017. https://doi.org/10.1016/j.cej.2017.04.051
[29] Colombo, V., Ghedini, E., Gherardi, M., Sanibondi, P. "Modelling for the optimization of the reaction chamber in silicon nanoparticle synthesis by a radio-frequency induction thermal plasma", Plasma Sources Science and Technology, 21, Article number: 055007, 2012. https://doi.org/10.1088/0963-0252/21/5/055007

[30] Samokhin, A. V., Alekseev, N. V., Kornev, S. A., Sinaiskii, M. A., Blagoveschenskiy, Y. V., Kolesnikov, A. V. "Tungsten Carbide and Vanadium Carbide Nanopowders Synthesis in DC Plasma Reactor", Plasma Chemistry and Plasma Processing, 33, pp. 605-616, 2013. https://doi.org/10.1007/s11090-013-9445-9

[31] Kuz'michev, E., Nikolenko, S. "Synthesis of titanium carbide from the rutile concentrate by low temperature plasma", E3S Web of Conferences, 56, Article number: 03026, 2018. https://doi.org/10.1051/e3sconf/20185603026

[32] Kim, D.-W., Heo, U. S., Kim, K.-S., Park, D.-W. "One-step Synthesis of TiC/multilayer graphene composite by thermal plasma", Current Applied Physic, 18(5), pp. 551-558, 2018. https://doi.org/10.1016/j.cap.2018.02.006

[33] Bai, L., Zhang, H., Jin, H., Yuan, F., Huang, S., Li, J. "RadioFrequency Atmospheric-Pressure Plasma Synthesis of Ultrafine $\mathrm{ZrC}$ Powders", International Journal of Applied Ceramic Technology, 10(s1), pp. E274-E281, 2013. https://doi.org/10.1111/j.1744-7402.2012.02816.x

[34] Mohai, I., Szepvölgyi, J. "Treatment of particulate metallurgical wastes in thermal plasmas", Chemical Engineering and Processing, 44(2), pp. 225-229, 2005. https://doi.org/10.1016/j.cep.2004.04.008

[35] Fazekas, P., Bódis, E., Keszler, A. M., Czégény, Z., Klébert, S., Károly, Z., Szépvölgyi, J. "Decomposition of Chlorobenzene by Thermal Plasma Processing", Plasma Chemistry and Plasma Processing, 33, pp. 765-778, 2013. https://doi.org/10.1007/s11090-013-9459-3

[36] Fazekas, P., Czégény, Z., Mink, J., Szabó, P. T., Keszler, A. M., Bódis, E., Klébert, S., Szépvölgyi, J., Károly, Z. "Thermal Plasma Decomposition of Tetrachloroethylene", Plasma Chemistry and Plasma Processing, 38, pp. 771-790, 2018. https://doi.org/10.1007/s11090-018-9895-1

[37] Bystrzejewski, M., Karoly, Z., Szepvolgyi, J., Kaszuwara, W., Huczko, A., Lange, H. "Continuous Synthesis of carbon-encapsulated magnetic nanoparticles with a minimum production of amorphous carbon", Carbon, 47(8), pp. 2040-2048, 2009. https://doi.org/10.1016/j.carbon.2009.03.054

[38] Szépvölgyi, J., Marković, Z., Todorović-Marković, B., Nikolić, Z., Mohai, I., Farkas Z., Tóth, M., Kováts, É., Scheier, P., Feil, S. "Effects of Precursors and Plasma Parameters on Fullerene Synthesis in RF Thermal Plasma Reactor", Plasma Chemistry and Plasma Processing, 26, pp. 597-608, 2006. https://doi.org/10.1007/s11090-006-9036-0

[39] Keszler, A. M., Fazekas, P., Bódis, E., Drotár, E., Klébert, Sz., Boselli, M., Ghedini, E., Sanibondi, P., Károly, Z., Szépvölgyi, J. "Optical Emission Spectroscopic Study of the Synthesis of Titanium Boride Nanoparticles in RF Thermal Plasma Reactor", Plasma Chemistry and Plasma Processing, 37, pp. 1491-1503, 2017. https://doi.org/10.1007/s11090-017-9836-4 
[40] Taylor, J. C. "Computer Programs for Standardless Quantitative Analysis of Minerals Using the Full Powder Diffraction Profile", Powder Diffraction, 6(1), pp. 2-9, 1991. https://doi.org/10.1017/S0885715600016778

[41] Mohai, M. "XPS MultiQuant: multimodel XPS quantification software", Surface and Interface Analysis, 36(8), pp. 828-832, 2004. https://doi.org/10.1002/sia.1775

[42] Mohai, M., Bertóti, I. "Calculation of overlayer thickness on curved curfaces based on XPS intensities", Surface and Interface Analysis, 36(8), pp. 805-808, 2004.

https://doi.org/10.1002/sia.1769

[43] Evans, S., Pritchard, R. G., Thomas, J. M. "Relative Differential Subshell Photoionization Cross-sections $(\mathrm{Mg} \mathrm{K} \alpha)$ from Lithium to Uranium", Journal of Electron Spectroscopy and Related Phenomena, 14(5), pp. 341-358, 1978. https://doi.org/10.1016/0368-2048(78)80008-5

[44] Reilman, R. F., Msezane, A., Manson, S. T. "Relative Intensities in Photoelectron Spectroscopy of Atoms and Molecules", Journal of Electron Spectroscopy and Related Phenomena, 8(5), pp. 389-394, 1976. https://doi.org/10.1016/0368-2048(76)80025-4

[45] Wagner, C. D., Riggs, W. M., Davis, L. E., Moulder, J. F., Muilenberg, G. E. "Handbook of X-ray Photoelectron Spectroscopy", Perkin-Elmer Corporation, Eden Prairie, MN, USA, 1979.

[46] Bertóti, I. "Nitrogen modified metal oxide surfaces", Catalysis Today, 181(1), pp. 95-101, 2012. https://doi.org/10.1016/j.cattod.2011.06.017

[47] GTT-Technologies "FACTSAGE Thermodynamic Equilibrium Software, (version 5.0)", [online] Available at: http://www.factsage. com/ [Accessed: 18 January 2020]

[48] Bernardi, D., Colombo, V., Ghedini, E., Mentrelli, A. "Threedimensional effects in the modelling of ICPTs", European Physical Journal D, 25, pp. 271-277, 2003. https://doi.org/10.1140/epjd/e2003-00244-0

[49] Bernardi, D., Colombo, V., Ghedini, E., Mentrelli, A. "Comparison of different techniques for the FLUENTC-based treatment of the electromagnetic field in inductively coupled plasma torches", European Physical Journal D, 27, pp. 55-72, 2003. https://doi.org/10.1140/epjd/e2003-00227-1

[50] Chang, Y., Pfender, E. "Thermochemistry of thermal plasma chemical reactions. Part I. General rules for the prediction of products", Plasma Chemistry and Plasma Processing, 7, pp. 275-297, 1987. https://doi.org/10.1007/BF01016518

[51] McFeaters, J. S., Stephens, R. L., Schwerdtfeger, P., Liddell, M. "Numerical modeling of titanium carbide synthesis in thermal plasma reactors", Plasma Chemistry and Plasma Processing, 14, pp. 333-360, 1994.

https://doi.org/10.1007/BF01447085
[52] Sajó, I. E. "X-ray Diffraction Quantitative Phase Analysis of Bayer Process Solids", In: Proceedings of the Xth Congress of ICSOBA-2008, Bhubaneshwar, India, 2008, pp. 71-76.

[53] Preiss, H., Berger, L.-M., Szulzewsky, K. "Thermal treatment of binary carbonaceous/ zirconia gels and formation of $\mathrm{Zr}(\mathrm{C}, \mathrm{O}, \mathrm{N})$ solid solutions", Carbon, 34(1), pp. 109-119, 1996. https://doi.org/10.1016/0008-6223(95)00147-6

[54] Barabash, O. M., Koval, Y. N. "Kristallicheskaya struktura i svojstva metallov i splavov" (Crystal Structure of Metals and Alloys), In: Handbook of structures and properties of metals and alloys, Naukova Dumka Kiev, Ukraine, 1986, pp. 215-216. [in Russian]

[55] Wang, J.-X., Ni, D.-W., Dong, S.-M., Yang, G., Gao, Y.-F., Kan, Y.-M., Chen, X.-W., Cao, Y.-P., Zhang, X.-Y. "Synthesis of nanocrystallized zirconium carbide based on an aqueous solution-derived precursor", RSC Advances, 7(37), pp. 22722-22727, 2017. https://doi.org/10.1039/C7RA02586F

[56] Oh, J.-H., Kim, M., Lee, Y. H., Hong, S.-H., Kim, T.-H., Choi, S. "Synthesis of Tungsten Carbide Nanomaterials in Triple DC Thermal Plasma Jet System", Journal of Nanoscience and Nanotechnology, 19(10), pp. 6277-6284, 2019. https://doi.org/10.1166/jnn.2019.17029

[57] Fronczak, M., Fazekas, P., Károly, Z., Hamankiewicz, B., Bystrzejewski, M. "Continuous and catalyst free synthesis of graphene sheets in thermal plasma jet", Chemical Engineering Journal, 322, pp. 385-396, 2017. https://doi.org/10.1016/j.cej.2017.04.051

[58] Dato, A, Frenklach, M. "Substrate-free microwave synthesis of graphene: experimental conditions and hydrocarbon precursors", New Journal of Physics, 12, Article number: 125013, 2010. https://doi.org/10.1088/1367-2630/12/12/125013

[59] Pellegrino, S., Thomé, L., Debelle, A., Miro, S., Trocellier, P. "Radiation effects in carbides: $\mathrm{TiC}$ and $\mathrm{ZrC}$ versus $\mathrm{SiC}^{\mathrm{C}}$, Nuclear Instruments and Methods in Physic Research B, 327, pp. 103-107, 2014.

https://doi.org/10.1016/j.nimb.2013.11.046

[60] Hao, Y., Wang, Y., Wang, L., Ni, Z., Wang, Z., Wang, R., Koo, C. K., Shen, Z., Thong, J. T. L. "Probing Layer Number and Stacking Order of Few-Layer Graphene by Raman Spectroscopy", Small, 6(2), pp. 195-200, 2010. https://doi.org/10.1002/smll.200901173

[61] Chase, M. W., Jr. "NIST-JANAF Themochemical Tables", Journal of Physical and Chemical Reference Data, Monograph 9, NIST National Institute of Standards and Technology, Gaithersburg, MD, USA, 1998. [online] Available at: https://webbook.nist.gov/ cgi/cbook.cgi? Source=1998CHA1-1951\&Units=SI [Accessed: 18 January 2020]

[62] Calderon V., S., Cavaleiro, A., Carvalho, S. "Chemical and structural characterization of Zr-C-N-Ag coatings: XPS, XRD and Raman spectroscopy", Applied Surface Science, 346, pp. 240-247, 2015. https://doi.org/10.1016/j.apsusc.2015.03.161 